\title{
Research on the Plastic Arts of Solon Tribe in Heilongjiang River Valley*
}

\author{
Hui Xie \\ Heihe University \\ Heihe, China 164300
}

\author{
Zhongfeng $\mathrm{Fu}$ \\ Heihe University \\ Heihe, China 164300
}

\begin{abstract}
Minority tribes and ethnic culture are the treasures of China's traditional culture, for they show the diversity and uniqueness of the culture in China, also they are an important part of the protection and inheritance of China's traditional culture. Solon tribe in Heilongjiang River Valley is a representative regional minority tribe in the north of China. Because its living area is in the closed mountain forest and grassland area, its primitive characteristics are obvious. Solon tribe strictly follows the traditional customs of life. Because of its living environment and the influence of regional culture, unique plastic arts and religious beliefs have been formed, and these contents are of great value for the research and exploration into China's regional ethnic culture. Here we carry out research on the plastic arts of Solon tribe in Heilongjiang River Valley based on the Shaman culture that Solon tribe believes in.
\end{abstract}

\section{Keywords-Solon tribe; plastic arts; Shaman culture}

\section{INTRODUCTION}

Chinese scholars have paid much attention to the research and inheritance of traditional ethnic culture, and the research on the primitive art of some ethnic tribes not only is a topic of domestic concern, but also has aroused wide attention internationally. As one of the representative minorities in the north of China, Solon tribe is characterized by remarkable diversity of its culture. With a local ethnic culture with distinctive features, Solon tribe has become the epitome of the development of ethnic culture in the north of China. Solon tribe owns rich cultural contents, among which unique plastic arts are there. It combines the daily dressing habits of ethnic minorities in the north of China with the artistic modeling style of Shaman culture, which is of great value for the study of ethnic minority culture in China. Here we have research and exploration into the plastic arts of Solon tribe in Heilongjiang River Valley based on the Shaman culture.

\section{SOlON TRIBE AND SHAMAN CULtURE}

\section{A. Solon Tribe}

Solon tribe is distributed in Heilongjiang River Valley,

*Project source: 2018 Heilongjiang provincial philosophy and social science planning project "Research on the Inheritance and Development of Plastic Arts of Solon Tribe in Heilongjiang River Valley between China and Russia" (project number: 18YSE614)
Hulunbeir City in Inner Mongolia and Tuscaloosa City in Xinjiang and other places in the north of China with a relatively sparse population and a wide distribution. People in the tribe often live in staggered communities where Mongolian, Oroqun and other ethnic groups are also there. Solon tribe has migrated many times in history, resulting in the multi-regional distribution at present. Solon people belong to a trans-boundary ethnic group. Evenks in Russia are also a clan tribe left by Solon people during their longterm migration. Solon tribe believes in Shamanism, so they are often married to close siblings. "Solon" is a name for the Oroqun people given by the Daur people, and it is interpreted as "people who lived in the forest". Because of their bravery and ability to fight, they were called Solons by the surrounding tribes. Solon tribe is not a specific ethnic entity; instead, it is a general name for various tribal groups in the surrounding areas. Solons belong to the Tunguska in terms of language family. For they have got along with the Mongolian and the Olunchun minorities in a friendly and harmonious way for a long time, so the language and ethnic culture and living customs of each other are absorbed, and this has a profound influence on the formation and development of plastic arts and ethnic culture of Solon tribe, which are deeply influenced by their living environment. They are a group of minority tribes with primitive life flavor that combine regional environment with local life culture.

\section{B. Shaman Culture}

Shamanism has distinct primitive characteristics, which can be traced back to ancient times. In many other regions of the world, Shamanism has similar primitive religious culture. Minorities in the north of China, in which Solon tribe is included, have believed in Shamanism since ancient times. Solon people created their own folk culture and plastic arts with their own ethnic characteristics according to the Shaman religious culture they believe in. There are no unified or specific worship objects in Shamanism, so it is of multi-god religious worship, which changes with different branches of ethnic groups and tribes. According to the analysis of the belief characteristics of Shamanism, with the development of social culture, Shamanism has gone through the following three stages: first, the nature worship phase, that is, the preliminary stage for the development of all cultural beliefs; then, the totem worship phase when Solon tribe began to create totems and other art cultures belonging to their own ethnic culture; finally, the earliest ancestor 
worship phase when Solon tribe began to inherit the characteristics of ethnic development by blood relationship. The original thought and basic philosophy of Shamanism is "animism". They believe that everything in the world is dominated by the "spirit" which can dominate everything and all things can be destroyed though the spirit exists forever. They believe in the existence of supernatural forces and believe that "masters" can control everything.

The main ritual of Shamanism is performed in the form of "sacrifice". In this way, Solon people pray to the nature and totem belief for production development, prosperity and harmony. They place all their hopes on spirit. Due to the difference of historical and geographical environment the tribe is in, the development of Solon tribe area is also unbalanced. According to the economic structure, the ethnic characteristics of Solon tribe is roughly divided into the following three types: first, Solon tribe mainly engaged in hunting and poultry raising; second, Solon tribe mainly engaged in animal husbandry; third, Solon people mainly engaged in agriculture while engaged in other economic activities at the same time. These three types are interlaced with each other. In the process of regional historical development, they have given the Solon ethnic group different ethnic cultural traits, thus forming the characteristics of diversity of Solon ethnic culture. The Shaman culture of Solon tribe is a kind of ethnic culture with primitive characteristics, which is mainly formed by connecting the hunting race to nature. We had an analysis from the perspective of cultural classification and inheritance, and found that Solon culture has the accumulation nature of cultural inheritance and it belongs to the distinct traditional culture. Therefore, the plastic arts evolved by Solon tribe from Shaman culture also conform to the characteristics and general laws of Chinese folk art.

\section{RESEARCH ON THE UNIQUE PlastiC ARTS OF SOLON} TRIBE

\section{A. Tribal Nature Worship Shapes the Plastic Arts}

In the Shaman culture of Solon tribe, the nature worship lasted for a long time. Due to the early origin of the tribe, in ancient times, the tribal culture with nature worship as the main belief shaped the unique plastic arts. On the Solon hats, Shaman clothing and the waistline of Shamanistic skirts, cloth strips of yellow, red, and blue colors were used as decoration. Among these decorations, blue represents the blue sky, lakes and rivers in nature, and it is the embodiment of natural events that takes blue as keynote in the life of the Solon tribe. Yellow represents the land where the clan lives and takes root. In this color full of love and affection for the land by the Solon people is there. Red represents fire. In traditional tribal life, fire is the main means to drive away wild animals and bake things. Therefore, Solon tribe attaches great importance to the embodiment of red cloth in clothing. These multicolored strips of cloth together represent the Rainbow God they worship. In addition, totems of different colors are also drawn on the Shaman drums of Solon people for decoration to show their respect to the Rainbow God, and this reflects their worship to nature.
In the Shaman costumes of Solon tribe, sun, moon and stars and other totem shapes are decorated. The iron round trimming hanging at the back of their costumes represents the sun. The machete-like iron trimming on the back represents the moon in nature. A row of circular ornaments made of copper pieces is decorated behind the Shaman costume. Seven pieces are there, which represents the Big Dipper. Finally, on the clothing at their back, there are thunder shapes that look like willow-leaf shapes hanging on the right and left sides. The antler shape decoration on the top is to compare the smallness of natural creatures with the majesty of Thor so as to express their worship of Thor. The back waistcoats of the Solon tribe are also decorated with the shape of the sun and the moon, which is reflected in the shape and color. Red is in a circle and it represents the sun. Yellow is of tooth form and it represents the moon.

\section{B. Plastic Arts for Totem Worship}

In the Shaman culture of Solon tribe, totem worship occupies a large proportion. Totem worship phenomenon is common in the tribe, and this comes from their primitive hunting life and the myths and legends spreading among the tribe.

1) Plastic art of deer totem: Decoration with deer totem as the main pattern is very common in the clothing of Solon tribe. This mainly comes from their primitive hunting activities. In the daily hunting activities, for some large mammals like to predate grazing animals for which deer is a representative, when hunting, Solon people always wear deer skin on their body and hide in the woods, also they take deer horn as decoration to disguise themselves so as to quietly get close to the wild animals for hunting. Therefore, in the whole process of camouflage hunting, people in the tribe have gradually developed a sense of mystery about the deer skin. They believe that the deer skin itself has a magical power and thus they have a feeling of worship for the deer skin. In addition, hunters have a better understanding of the body structure and living habits of deer in the daily hunting process, so the basis for making deer costume is formed. The double deer horns on the Shaman hats of the Solon tribe are also a reflection of the totemic culture. On the other hand, it is mixed with the concept of "toro" tree in Shaman culture. In the traditional mythology of the Solon tribe, deer horns are often combined with sacred objects in the sky, so this is both worship of deer and worship of sacred trees. The Shaman clothing of the Solon tribe is decorated with obvious deer horns and bones, and black wide strips of $10-16 \mathrm{~cm}$ are added at the sleeves of the clothes. At the same time, the same black cloth strips were added at the front of the clothes. This decoration actually symbolizes the limbs and body structure of the deer. In addition, they use the sun, the moon and the mountains and rivers and trees as the background to echo the totem of deer, reflecting the reverence for the deer totem.

2) Plastic art of snake totem: In Solon people's eyes, the snake was their Lord God. When the Shamans visit a patient, 
they often take a snake off their clothes and store it in the home of the patient, so that the patient can make offerings to it until the disease gets better. In clothing, the snake decoration is mainly decorated on the Shaman skirt belt, and the snake decoration is made of animal skin. The fur with two colors of large difference is sewn in the shape of a ring, and then cross-sewing shall be done according to different colors so as to create the snake shape. However, this kind of decoration does not own a snake head. The snakeskin decoration is mainly made of white board skin of long strip shape, and crosswisely, blue, red and blue form a set of lineadorning, constituting decorations on the snakeskin. By the end it can be tailored as fur strips to be a tail ornament of the snake skin. This is also an adornment without a snake head. Finally, put a piece of snakeskin strip on snake fur shape and sew them together to form a skirt stripe. There are two kinds of snake skin decorations, the long one is about $55 \mathrm{~cm}$, and the short one is about $35 \mathrm{~cm}$, and the diameter is about $3 \mathrm{~cm}$. In all 36 pieces are there. At the bottom of decorations for double antlers of the Shaman hats of the Solon people, colored ropes twisted by cloth of different colors are also there, which gradually lowered from the back of the hats to the shoulders. This colored rope decoration is a remarkable reflection of the snake totem culture in the clothing. In addition, artistic works decorated with snake as the main totem are there in the paintings and sculptures of Solon gods of Solon tribe.

3) Plastic art of eagle totem: In the Shaman culture of Solon tribe, decorative pattern that takes eagle totem as the main body is reflected in Shaman hats. The appearance of eagle totem is relative to the fact that eagle is a raptor. Since ancient times Solon people have taken hunting as their major activity, thus the eagle, a raptor, became the worship object of Solon people and was integrated into the costumes and decorations. In costumes, they often insert bronze or wooden eagle shapes into the double antlers of Shaman hats to highlight their worship of eagle totem.

4) Plastic art of bear totem: For Solon people, the bear totem shape is often seen on the back of Shaman drums. A bear made of iron pieces is often hung on the right and left sides of the dress in costumes, so as to highlight eagle totem. In the primitive legends and tales of Solon tribe, because the bear is of huge size and can stand, and it is of distinctive arms and legs, bear is regarded as the embodiment of people. This view is commonly accepted by the tribe. In addition, because of the status the bear is in in the hunting activities, the worship of the bear is formed, which gradually evolved into some folk culture about bear. The Solon people believe that bears are the protection gods of deer. Because of the existence of bears, wolves dare not harm reindeer easily, so they worship bears. Although there are few decorations of bear totem in clothing, it still reflects the positive attitude of Solon tribe towards bears, so it can be called as the plastic art of "bear totem culture".

\section{Plastic Art for Earliest Ancestor Worship}

From totem worship to the earliest ancestor worship, it is a development transition period from object worship to plastic art worship. The Shaman culture of Solon tribe entered the period of earliest ancestor worship from totem worship, and this gave birth to the people-oriented plastic art thought. The composition of Shaman culture changed from the simple worship of animal totem in the past hunting period to various fields of tribal life, thus a social culture based on ethnic group is gradually formed. During this period, the painting art of some idol figures also changed from animal to human. It is reflected in the clothing of mainly the representatives of the tribe. There were four or five rectangular pieces of leather on the front of their garment as ornaments, and on each piece of leather there are flowers and deer horn decorations as well. These are meant to represent the number of tribal representatives. Under the leather piece, copper bells or long waist bells are hung at the same time, which is the representative and symbol of the members of the clan. These decorations clearly symbolize the member relations in the clan and tribe. At the same time, it clearly reflects the social status of members.

In the aspect of spiritual idol painting and sculpture, the painting pattern has changed from the past gods of nature, totem, animal and hunting to the gods with people as the main symbol. For the mountain god as an example, it the past, people in the tribe worship of trees and the natural environment in the mountains, but now they enshrine and worship the bearded old people depicted on the trunks or foundations. In terms of sacrifice, animal totems hanged in the period of nature worship were gradually replaced by human being, and the sacrifice rites that take people as the main worship objects appeared.

\section{CONCLUSION}

To sum up, the Shaman culture of Solon tribe is an ethnic culture with distinct primitive characteristics, and it develops and changes with the evolution of the lifestyle of the tribe. Shamanism, as the primitive religion believed in by Solon tribe, has exerted a profound influence on its ethnic culture and plastic arts. Under the religious belief of "animism", worship idols and plastic arts decorations in different forms such as nature worship, totem worship and animal worship were produced. Traditional hunting activities also shaped the Solon people's cognition of worship objects. Deer, snakes, eagles and bears all reflect Solon people's worship of animals and respect for nature. On the other hand, under the influence of Shamanism culture, the development of plastic arts has a long and tortuous history. On the basis of their own lives, they explore the cognition of beauty and reflect the breath of art with their opinions on life. In a word, the plastic arts and ethnic culture of Solon ethnic group are the results accumulated by the long-term living practice of the Solon ethnic group, and the worship of faith and the cognition of beauty by Solon people are embodied in them. This kind of plastic art based on life is an important part of traditional cultural treasures of China. It perfectly shows the characteristics of the diversity of China's ethnic culture. It is the epitome of life of Solon tribe and the inheritance and 
embodiment of its development history. What's more, it is the wisdom crystallization of the daily life of people in the north. Therefore, the research on the Shaman culture and plastic arts of Solon tribe is of significant research value to the ethnic history and traditional culture of China

\section{REFERENCES}

[1] Fan Tieming. Research on traditional costumes and plastic art of Daur nationality in Nenjiang river basin of Heilongiiang Province. Theoretic observation, 2015.1.

[2] Sun Yunlai trans. The plastic art of Heilongiiang tourism nation. Tianjin ancient books publishing house, 1990. 